\title{
ENTRE A FALIBILIDADE HUMANA E O ERRO: PROPOSTA DE DELIMITAÇÃO E CLASSIFICAÇÃO DO ERRO MÉDICO
}

\section{Gustavo Silveira Borges ${ }^{1}$}

\section{Resumo}

Este artigo objetiva discutir o erro médico, apresentando as limitações entre a falibilidade humana e o erro. Nesta seara, investiga-se a culpa e o erro profissional. Ademais, estuda-se a delimitação jurídico-civil e as consequências do erro médico, propondo-se, ao final uma classificação a partir de uma tipologia das espécies de erro médico. Por fim, trabalha-se com a questão envolvendo a iatrogenia. Por meio de uma análise bibliográfica e documental, promove-se um diálogo entre os aportes da responsabilidade civil e os limites do erro e da falibilidade humana. Por fim, conclui-se que o erro médico pode ser classificado em erro de diagnóstico, erro de tratamento e, erro na relação com o paciente.

Palavras-chaves: Erro Médico; Classificação; Responsabilidade Civil; Código Civil; Código de Defesa do Consumidor

\section{INTRODUÇÃO}

Todo o ser humano é falível. O erro faz parte desta condição. Tal circunstância encontra-se incorporada no aforismo latino "errare humanum est". Todavia, já que a falibilidade é elemento inerente à própria condição humana, deve-se evitar, de todas as maneiras, a persistência no erro ("sed diabolicum perseverare"), uma vez que errar é humano, mas diabólico é nele perseverar. ${ }^{2}$

O erro, elemento indissociável da vida humana, entretanto, pode ser minimizado, ou até mesmo eliminado em determinadas situações, quando se age com a devida atenção, cuidado e diligência a fim de evitá-lo. Este erro, quando ocorre, pode gerar, muitas vezes, lesão ou perigo de lesão a bens jurídicos pessoais, tais como a integridade física, a saúde e até a própria vida da pessoa. $\mathrm{Na}$ atividade médica, o fracasso na realização dos objetivos médicos não implica considerar, por si só, o cometimento do erro e a causação de danos ao paciente, em vista desta própria qualidade inseparável do ser humano, ${ }^{3}$ o que deve ser analisado caso a caso.

A questão envolvendo o erro médico, mais precisamente a necessidade de uma classificação das suas

\footnotetext{
${ }^{1}$ Pós-Doutor em Direito pela Universidade do Vale do Rio dos Sinos - UNISINOS. Professor do Curso da Faculdade de Direito da Universidade do Extremo Sul Catarinense - UNESC - Criciúma/SC. E-mail: gustavoborges@hotmail.com.

${ }^{2}$ RODRIGUES, Álvaro da Cunha Gomes. Responsabilidade civil por erro médico: esclarecimento/consentimento do doente. Revista Data Venia, núm. 01, jul.-dez., 2012, p. 06.
} 
espécies o Direito ainda não lhe deu a devida e merecida atenção, o que se faz com o presente trabalho.

Há um grande desafio a ser enfrentado, não resta dúvida. Neste sentido, o presente trabalho tem como objetivo realizar um estudo do erro médico, quais os seus limites e classificações possíveis. Primeiramente, apresentam-se ponderações sobre a culpa e o erro profissional. Posteriormente, será apresentada a delimitação jurídico-civil, demonstrando-se quais as consequências do erro médico. Por fim, será tratada e proposta uma classificação dos tipos de erro médico, assim como a distinção em relação à iatrogenia.

Tais reflexões têm com o objetivo responder as seguintes indagações: qual é a diferença entre a culpa e o erro profissional? Qual a classificação dos tipos de erro médico? E, por derradeiro, qual a diferença entre o erro médico e a iatrogenia?

Por fim, o presente ensaio é relevante porque se trata de uma preocupação presente na sociedade pósmoderna, qual seja, a do exponencial crescimento das demandas por erro médico.

\section{A FALIBILIDADE HUMANA, O RISCO INERENTE DA ATIVIDADE MÉDICA E OS LIMITES DE CONTATO COM O ERRO MÉDICO}

De início, cabe mencionar que a palavra "erro" apresenta plurissignificação, incluindo, em determinadas situações, a própria noção de "culpa". O "erro" tanto pode consistir na circunstância de uma afirmação resultar numa falsidade, como pode expressar uma falsa representação da realidade.

A menção do termo "erro", automaticamente, remete à noção de que o médico fez algo errado, causando algum tipo de mal ao paciente. Ao se adotar a expressão "erro médico", leva-se a crer que, pré-conceitualmente, já se incorreu num equívoco, pois a culpa parece estar imputada com a palavra erro. E ninguém pode ser considerado culpado sem que sejam devidamente apurados os seus aspectos judicantes. Como alude Silva, " $O$ chamado erro médico não é a melhor expressão. Erro, na órbita jurídica, é vício existente na manifestação de vontade, que anula um negócio jurídico, nos termos dos arts. 138 a 144 do Código Civil. Quando é utilizada a expressão erro médico, seu significado é de atuação negligente, imperita ou imprudente, isto é, de culpa em sentido estrito, que pode levar à aplicação do princípio da reparação dos danos, conforme art. 186 do Código Civil ${ }^{n+4}$

De qualquer forma, tendo em conta as críticas expostas às questões terminológicas, em vista ser predominantemente a mais recorrente tanto pela doutrina, quanto pela jurisprudência nacional, adotar-se-á esta

\footnotetext{
${ }^{3}$ FRADERA, Véra Maria Jacob de. Responsabilidade civil dos médicos. Revista AJURIS 55. Porto Alegre, jul. 1992, p. 129.

${ }^{4}$ SILVA, Regina Beatriz Tavares da. Pressupostos da responsabilidade civil na área da saúde: ação, dano e nexo causal. Fundamentos da responsabilidade civil na área da saúde: culpa ou risco. A prova. In: SILVA, Regina Beatriz Tavares da. (Org.). Responsabilidade civil na área da saúde. 2.ed. São Paulo: Saraiva, 2009, p. 26.
} 
nomenclatura no presente texto. ${ }^{5}$

$\mathrm{Na}$ análise do erro, em especial do erro médico, o que deve sim ser levado em conta é o processo deste errar. Há uma linha tênue entre a conduta médica e o risco intrínseco que ela consigo carrega. Direito e Cavalieri Filho propõem, como critério para aferição do erro do médico, tendo como parâmetros de comparação o ponto de interrupção entre a fatalidade e a falta de diligência necessária para o exercício da profissão como passível de responsabilização civil, que se deva avaliar se o médico agiu de acordo com as técnicas médicas de seu tempo, utilizando todos os recursos disponíveis. Se agiu desta forma, o erro será escusável, sendo avaliado pelo Magistrado em cada caso concreto. Do contrário, teremos o erro do médico como inescusável e a sua posterior responsabilização. ${ }^{6}$

A falibilidade médica só ingressará na seara de punição em dois casos: a) nas falhas relativas aos deveres de humanidade, como, por exemplo, deixar de socorrer um doente, e; b) nas falhas de natureza técnica, como nos casos de erro de diagnóstico, erro de prognóstico, dentre outros casos nos quais se configura a culpa médica?

Podem-se considerar como puníveis certas técnicas ainda que não classificadas como científicas, denominadas condutas não-médicas ${ }^{8}$, de quem atua à margem dos limites do conhecimento científico, fora da legislação, por leigos, por exemplo. Caso a materialização dessa conduta não-médica seja realizada por profissional médico, com a atitude de apostar em suposições prognósticas, desprovidas de qualquer procedência científica, totalmente distante do conhecimento médico, ficará agravada, podendo, inclusive, ser punida no âmbito éticodisciplinar e penal.

O risco, inerente à atividade médica, é questão que circunda o ato médico. Há circunstâncias que são imprevisíveis e que podem gerar consequências graves ao paciente, devendo-se responsabilizar o médico por danos em face do ato médico somente nos casos em que o risco é completamente previsível. Exigir-se, de forma

\footnotetext{
${ }^{5}$ Conforme exposição da conclusão do relatório final dos trabalhos da Comissão Parlamentar de Inquérito, instaurada pelo Ato no 58 de 2009, com a finalidade de investigar informações divulgadas pela imprensa de erros cometidos por médicos no Estado de São Paulo, conforme Requerimento no 1150, de 2007, relatada pelo Deputado Uebe Rezeck, da qual o termo final da denominada "CPI do Erro Médico" se dêu em 03 de fevereiro de 2010, com o seguinte termo que transcrevemos parcialmente: "faz-se necessária uma reflexão sobre: o que é erro médico? "Segundo o magistrado José Idelfonso Bizatto, "... o erro médico, no campo da responsabilidade pode ser de ordem pessoal ou de ordem estrutural. É estritamente pessoal quando o ato lesivo se deu, na ação ou omissão, por despreparo técnico e intelectual, por grosseiro descaso ou por motivos ocasionais referentes às suas condições físicas ou emocionais. Pode também o erro médico ser procedente de falhas estruturais, quando os meios ou condições de trabalho são insuficientes ou ineficazes para uma resposta satisfatória” SÃO PAULO. Assembleia legislativa. Relatório final da comissão parlamentar de sobre erro médico. <http://www.al.sp.gov.br/StaticFile/documentacao/cpi_erro_medico_relatorio_final.pdf >.Acesso em: 25 jan. 2017.

${ }^{6}$ DIREITO, Carlos Alberto Menezes; CAVALIERI FILHO, Sérgio. Comentários ao novo código civil, volume XIII: da responsabilidade civil, das preferências e privilégios creditórios. - Rio de Janeiro: Forense, 2004, pp. 437-441.

${ }^{7}$ MELLO FILHO, Jonas de. Erro médico. In: PEREIRA, Hélio do Valle; ENZWEILER, Romano José. Curso de direito médico. São Paulo: Conceito Editorial, 2011, p. 336.

${ }^{8}$ Os autores exemplificam uma conduta não-médica, realizada por médico, a prática de abuso sexual em paciente submetida a exame ginecológico. FERRAZ, Edmundo Machado; NOGUEIRA, Roberto Wanderley. Erro médico e prática não médica. In:
} 
diversa, estar-se-ia equivalendo a conduta médica a uma espécie de conduta divina. Dentro desta perspectiva da falibilidade humana, é importante se definir os limites entre a falibilidade humana e o erro médico. Estes são balizados pelo erro escusável e inescusável.

O erro escusável não configura a culpa médica, pois, neste caso, a conduta médica foi diligente e de acordo com os deveres jurídicos essenciais exigidos do médico. Conforme Aguiar Júnior, "há erro escusável, e não imperícia, sempre que o profissional, empregando correta e oportunamente os conhecimentos e as regras da sua ciência, chega a uma conclusão falsa, possa, embora, advir daí um resultado de dano ou de perigo". Portanto, se o médico agiu de acordo com as regras técnicas atualizadas das ciências médicas, cumprindo com todos os seus deveres jurídicos essenciais, eventual erro que porventura ocorra, reconhece-se como escusável, desprovido de caráter punitivo-indenizatório. ${ }^{10}$

Explicitados os limites, ainda, surgem alguns conceitos, como: o acidente imprevisível ${ }^{11}$, o resultado incontrolável ${ }^{12}$ e as complicações.

O erro médico oriundo de um acidente imprevisível é o resultado lesivo ${ }^{13}$ advindo de caso fortuito ou força maior, incapaz de ser previsto ou evitado, qualquer que seja o autor em idênticas circunstâncias. Por outro lado, o resultado incontrolável é aquele decorrente de situação incontornável, de curso inexorável, próprio da evolução do caso - quando, até o momento da ocorrência, a ciência e a competência profissional não dispõem de solução. No acidente imprevisível, há um resultado lesivo supostamente oriundo de caso fortuito ou força maior, à integridade física ou psíquica do paciente durante o ato médico. Por exemplo, o caso de um cirurgião que vai executar um procedimento e lesa inadvertidamente o paciente, promovendo-lhe danos. Se o cirurgião devidamente habilitado realizou o ato com toda cautela e teve um mau resultado, obviamente não poderá responder pelo dano, pois não se trata de erro médico e sim, um acidente imprevisível.

FIGUEIREDO, Antônio Macena de; LANA, Roberto Lauro. Direito médico: implicações éticas e jurídicas na prática médica. Rio de Janeiro: Lumen Juris, 2009, p. 355.

9 AGUIAR JÚNIOR, Ruy Rosado de. Responsabilidade civil do médico. Revista Jurídica: órgão nacional de doutrina, jurisprudência, legislação e crítica judiciária. Ano XLV, n. 231, 1997, p. 128.

${ }^{10}$ CARVALHO, José Carlos Maldonado de. Iatrogenia e erro médico sob o enfoque da responsabilidade civil. 3.ed., rev. e ampl. Rio de Janeiro: Editora Lumen Juris, 2009, p. 59.

${ }^{11}$ França alude que acidente imprevisível é "um resultado lesivo, supostamente oriundo de caso fortuito ou força maior, à integridade fisica ou psíquica do paciente durante o ato médico ou em face dele, porém incapaz de ser previsto e evitado, não só pelo autor, mas por outro qualquer em seu lugar.”FRANÇA, Genival. Direito médico. - 11.ed., rev., atual. e ampl. - Rio de Janeiro: Forense, 2013, p. 253.

${ }^{12}$ França diz que resultado incontrolável é "decorrente de uma situação grave e de curso inexorável. Ou seja, aquele resultado danoso proveniente de sua própria evolução, para o qual as condiçóes atuais da ciência e a capacidade profissional ainda não oferecem solução. "FRANÇA, Genival. Direito médico, p. 253.

${ }^{13}$ GOMES, Júlio Cezar Meirelles; FRANÇA, Genival Veloso de. Erro médico. In: COSTA, Sergio Ibiapina Ferreira; OSELKA, Gabriel; GARRAFA, Volnei. (orgs.) Iniciação à bioética. - Brasília: Conselho. Federal de Medicina, 1998, pp. 244-245. 
O resultado incontrolável seria aquele decorrente de uma situação grave e de curso inexorável. Ou seja, aquele resultado danoso proveniente de sua própria evolução, para o qual as condições atuais da ciência e a capacidade profissional ainda não oferecem solução. ${ }^{14}$

Sobre a distinção entre erro propriamente dito e acidente, e entre este conceito e o de complicação, Moraes alude que o acidente é "a ocorrência desagradável não esperada mas previsível, como as intercorrências que acontecem, tanto no processo diagnóstico, como no terapêutico, como são, por exemplo, os acidentes radiológicos, anestésicos e cirúrgicos".

E a complicação seria "o aparecimento de uma nova condição mórbida no decorrer de uma doença, devida ou não à mesma causa. ${ }^{15}$ Por detrás de um acidente ou de uma complicação, pode estar um erro de percepção ou cognitivo (como um erro de diagnóstico, da errada interpretação da sintomatologia do paciente ou de dados laboratoriais, em face de deformada ou distorcida percepção da realidade); ou um erro de execução, como o manejo indevido de instrumentos na realização do ato clínico ou cirúrgico ou troca de produtos farmacológicos no tratamento do paciente. ${ }^{16}$

O erro médico ocorre, então, quando a técnica aplicada é a adequada, mas a atuação do médico é incorreta. Tal erro é civilmente punível, por denominar-se "erro inescusável”, não justificável; ensejando, então, o dever de reparar.

\section{A culpa e o erro profissional}

Outra expressão designada que merece a delimitação quanto ao alcance jurídico é o erro profissional ${ }^{7}$, também denominada de erro escusável, erro de técnica ${ }^{18}$.

A diferença entre culpa médica erro profissional, muitas vezes utilizado erroneamente como sinônimo de negligência, está em que o erro profissional ocorre quando a conduta médica é correta, mas a técnica empregada é incorreta; haverá culpa médica quando a técnica utilizada for correta, mas a conduta médica for considerada incorreta. ${ }^{19}$

O erro profissional é aquele que advém de uma falha não imputável ao médico, em face das naturais limitações científicas. Neste caso, incluem-se as situações nas quais o médico procedeu de forma correta, mas o paciente omitiu informações e não colaborou, descumprindo os seus deveres de fornecer subsídios à indicação

\footnotetext{
${ }^{14}$ MINOSSI, José Guilherme. Prevenção de conflitos médico-legais no exercício da medicina. Revista do Colégio Brasileiro de Cirurgiöes, vol.36, núm.1, 2009, p.91.

${ }^{15}$ MORAES, Irany Novah. Erro médico e a justiça. 5.ed. rev., atual. e ampl. - São Paulo: Editora Revista dos Tribunais, 2003, p. 493.

${ }^{16}$ RODRIGUES, Álvaro da Cunha Gomes. Responsabilidade civil por erro médico: esclarecimento/consentimento do doente. Revista Data Venia, n. 01, jul.-dez., 2012, p. 10.

${ }^{17}$ GIOSTRI, Hildegard Taggesell. Erro médico à luz da jurisprudência comentada. 2.ed. Curitiba: Juruá, 2004, p. 76.

${ }^{18}$ STOCO, Rui. Iatrogenia e responsabilidade civil do médico. Revista dos Tribunais, vol.789, 2001, pp. 109.
} 
diagnóstico-terapêutica. Nestes casos, o erro ficará configurado, mas não se poderá imputar a culpa ao profissional em razão das limitações da profissão, assim como da natureza humana, sendo considerado um erro escusável, excluindo-se, desta forma, a responsabilidade civil médica. Ocorre quando resulta da incerteza ou da imperfeição da arte e não de negligência ou incapacidade de quem a exercita, excepcionando-se os casos de erro grosseiro. É insuscetível de responsabilização do médico, que ocorre quando a conduta médica é correta, mas a técnica empregada é incorreta, da culpa que ocorre quando a técnica é correta, mas a conduta é incorreta. Erros acontecem, mas não podem ser tomados sempre como aberrações. Não se trata de buscar o médico infalível, nem se pode buscar uma ciência acima de qualquer erro, sendo este o ponto da dificuldade do erro que tem como efeitos deletérios a responsabilidade civil. Como alude Stoco, "a imperfeição da ciência é uma realidade. Daí a escusa se tolera a fatabilidade do profissional."20 Nestes casos, não caberá ao juiz dizer se a técnica é boa ou inadequada, ou ainda se há outra melhor. O erro, desde que a técnica utilizada seja conhecida e aceita por grande parte da literatura médica, deve ser escusável para que se isente o médico da responsabilização.

A violação dos deveres jurídicos essenciais por parte do médico enseja a caracterização da culpa, que é dividida nas três espécies: negligência, imprudência e imperícia. Em sede de responsabilidade civil médica. Também a manutenção de elevados padrões na prática diária com formação contínua e documentação de todos os procedimentos são todos uma defesa suficiente do médico em caso de litígio.

O erro profissional decorre, portanto, da imprecisão, incerteza ou imperfeição da arte médica ${ }^{21}$, sendo a culpa, nas suas modalidades de imperícia, imprudência e negligência, que caracteriza a ocorrência do erro médico. No erro profissional, estar-se-á diante de um quadro de probabilidade decorrente da incerteza científica, e não da incapacidade de exercício técnico do profissional. O médico só poderá ser responsabilizado por atos que dependam de sua atenção e técnica, e não por fatores externos, que independem do seu atuar, do seu conhecimento. ${ }^{22}$ A culpa médica supõe a falta de diligência ou de prudência em relação ao que era esperável de um bom profissional escolhido como padrão; o erro é a falha do homem normal, consequência inelutável da falibilidade humana.

A culpa se consubstancia na ausência de um dever de cuidado que o médico possui em relação aos meios necessários para o tratamento do paciente, pressupondo a falta de diligência e atenção, bem como a devida técnica que é esperada do médico no exercício da profissão. A culpa, portanto, será analisada a partir da comparação em relação ao que se esperaria de um bom profissional escolhido como padrão. Esse é o entendimento do Superior

\footnotetext{
${ }^{19}$ CAVALIERI FILHO, Sérgio. Programa de responsabilidade civil. 8.ed. - São Paulo: Atlas, 2008, p. 372.

${ }^{20}$ STOCO, Rui. Tratado de responsabilidade civil: doutrina e jurisprudência, p. 660.

${ }^{21}$ ANDREONI, Wilson Rubens. Cirurgia plástica - obrigação de meio. In: AVELAR, Juarez Moraes. Cirurgia plástica: obrigação de meio e não obrigação de fim ou de resultado, p. 426.

${ }^{22}$ SOUZA, Alex Pereira de; COUTO FILHO, Antônio Ferreira. A improcedência no suposto erro médico, Rio de Janeiro: Lumen Juris, 2002 p. 14-15.
} 
Tribunal de Justiça que já se manifestou aludindo que "a culpa médica supóe uma falta de diligência ou de prudência em relação ao que era esperável de um bom profissional escolhido como padrão; o erro é a falha do homem normal, consequência inelutável da falibilidade humana. E, embora não se possa falar de um direito ao erro, será este escusável quando invencivel à mediana cultura médica, tendo em vista circunstâncias do caso concreto. ${ }^{23}$

Desta forma, o erro de técnica não se confunde com o erro médico, não se devendo nos casos controvertidos ou duvidosos considerar que houve imperícia, imprudência ou negligência. No erro profissional, há o erro escusável, já que a conduta médica é correta, mas a técnica empregada é incorreta, significando que o médico aplica corretamente uma técnica ruim ou duvidosa, embora aceita e defendida na literatura; já no erro inescusável, há imperícia, não se justificando, nem se admitindo, impondo-se, no caso, o dever de indenizar. ${ }^{24}$ Desta maneira, preenchidos os requisitos, presume-se que um profissional está habilitado para a tomada de decisões médicas, dentro da sua discricionariedade médico-científica, de qual o melhor tratamento para o paciente e só será responsabilizado se agir grosseiramente, com imperícia, imprudência e negligência.

\section{Delimitação jurídico-civil e as consequências do erro médico}

Ao recortar a temática sob o aspecto jurídico-civil, assim como as suas consequências, cabe, inicialmente, trazer à tona a discussão acerca da terminologia correntemente utilizada pela doutrina e pela jurisprudência "erro médico".

Para delimitação jurídico-civil do tema, parte-se da compreensão do ato médico e quais os possíveis fatores causais que podem levar à ocorrência do erro médico.

O ato médico "é toda a actuação directa ou indirecta sobre um organismo humano por parte de um médico (ou equipa de médicos), no exercício da sua profissão, para a qual tem o devido título académico de licenciado em medicina e cirurgia”25. Está disciplinado na Resolução CFMn 1. 1.627/2001 do Conselho Federal de Medicina, sendo definido no art. $1^{\circ}$ como todo procedimento técnico-profissional praticado por médico legalmente habilitado com o objetivo geral de prestar assistência médica, investigar as enfermidades ou a condição de enfermo ou ensinar disciplinas médicas. É função privativa de quem é formado em Medicina, em estabelecimentos educacionais oficiais ou oficialmente reconhecidos.

\footnotetext{
${ }^{23}$ Veja-se no julgado: BRASIL. Superior Tribunal de Justiça. Recurso Especial no 904.682/RS. Terceira Turma. Recorrente: Antônio Carlos Dalla Costa. Recorrido: Maristela Tavares. Relator: Min. Ricardo Villas Bôas Cueva. Rio Grande do Sul/RS, em 12/11/2012. Disponível em: $<$ https://ww2.sti.jus.br/processo/jsp/revista/abreDocumento.jsp? componente=MON\&sequencial=25353949\&formato=PDF > Acesso em: 25 jan. 2017.

${ }^{24}$ STOCO, Rui. Tratado de responsabilidade civil: doutrina e jurisprudência, p. 661.

${ }^{25}$ LÓPEZ, Pedro Rodríguez. Responsabilidad médica y hospitalaria. Bosch, 2004, pp. 34-35.
} 
Alguns critérios devem ser observados na realização do ato médico: 1) Critério profissional, na medida em que só pode ser praticado por médico que possui um "título habilitante"; 2) A execução deve ser típica e regular, respeitando às "legis artis ad hoc", que impõem ao médico que atue com diligência e utilizando-se das técnicas normais exigidas pelo caso em concreto; 3) O objetivo da atividade médica deve ser o de prestar assistência médica, investigar as enfermidades ou a condição de enfermo ou ensinar disciplinas médicas e; 4) A conduta deve ser lícita, já que praticado em conformidade com os princípios do "consenso social" ou, de outro modo, aceita por toda a coletividade e em conforme a lei. ${ }^{26}$ Dentro destes atos médicos, Pedro Rodríguez considera que a atividade do médico engloba diferentes tipos: a) Atos de prevenção, que visam a adotar as medidas necessárias para evitar que a doença se verifique; b) Atos de diagnóstico, com vista a determinar a natureza e origem da doença do paciente, que se verificou dos exames e análises clínicas; c) Atos de prescrição, os quais têm por missão determinar a terapêutica que o paciente deve seguir, após a realização do seu diagnóstico; d) Atos de tratamento - que se traduzem na execução de medidas idóneas à cura ou melhora do doente; e) Atos de reabilitação, que supõem todo um conjunto de ações dirigidas ao restabelecimento do paciente (órgão, membro) ao seu estado saudável e; f) Outros atos médicos. ${ }^{27}$

Na realização destes atos médicos, podem-se identificar alguns fatores causais potenciais geradores de erro médico que são, basicamente, resumidos em quatro grupos distintos: a) O processo psíquico de formação de juízo, em que tenha faltado a confrontação com parâmetros ou critérios reconhecidos como corretos e adequados no particular âmbito de exame, sendo que tal juízo não é validado. Neste caso, o médico pode provocar o erro de diagnóstico, já que poderia ter sido facilmente evitado mediante prévia comprovação técnica; b) Os parâmetros em questão foram corretamente utilizados, mas a dedução ultrapassou os limites da sua aplicabilidade. Nesta situação, a imperícia resulta de fatos praticados sem a devida "autorização" por parte da ciência médica; c) O parâmetro válido às finalidades de avaliação revela-se "estranho" no âmbito em que se desenvolve a investigação crítica, verificando-se, assim, um "desajustamento" teórico e científico, nocivos ao tratamento do paciente. Neste caso, foi utilizado um critério que não era válido no caso concreto, podendo existir ou não culpa, conforme o "erro" se deva ou não a um vácuo da ciência médica, à apresentação pelo paciente de sintomas desconcertantes e suscetíveis de causar equívocos no espírito do médico ou à falta de meios de investigação adequados e, por fim; d) O parâmetro é apropriado, mas incapaz de discriminar o problema de saúde do paciente, no caso concreto. É a situação em que mais claramente se pode constatar que o "erro" não implica a responsabilidade civil, porquanto o médico faz tudo o que está ao seu alcance para ajudar o paciente, e ainda assim, não consegue alcançar o efeito

\footnotetext{
${ }^{26}$ SOUSA, Isa António de. A responsabilidade do Estado por actos médicos: entre a "présomption de faute" francesa e a "objectivização" espanhola - breve resenha comparativa: uma convergência de regimes? Revista da Faculdade de Direito da Universidade Lusófona do Porto, vol. 2, núm. 2, 2013, pp. 97-98.

${ }^{27}$ LÓPEZ, Pedro Rodríguez. Responsabilidad médica y hospitalaria. Bosch, 2004, pp. 341-342.
} 
almejado; nem pode ter a certeza de que terá êxito no tratamento e cura do paciente, atendendo ao juízo médicocientífico e ao critério do "bom profissional de saúde" ${ }^{28}$ Desta forma, é necessário estabelecer as diferenças entre o erro médico e certas figuras que, com ele, apresentam afinidades.

Como diz Fragata, "o erro é cinzento na cor, sinistro no perfil e amargo no travo (sabor)", "um dos segredos mais mal guardados da profissão". ${ }^{29}$ E segue, "o erro, sinônimo de negligência - pior ainda, de falta de carácter - ocasiona profundo impacto pessoal e profissional. É vivido em dramática solidão" ${ }^{30}$ Concorda-se com Direito, que alude que "não se deve falar em erro médico, mas erro do médico"3. ${ }^{\text {N1 }}$ No Direito Francês, utiliza-se o termo erreur em distinção ao faute medicale. Penneau diferencia erro, como uma falha do homem normal, que pode ocorrer com todo bom profissional em decorrência de uma falibilidade humana inevitável, independentemente de qualquer negligência ou imprudência e falta médica, como sendo falta de diligência ou cuidado em relação a um bom padrão profissional. Esta diferenciação não é feita na jurisprudência brasileira, o que significa dizer que, na prática, muitas vezes, se está a condenar médicos por erro escusável, fato que não se pode admitir em face da necessidade de comprovação da culpa médica somente nos casos de erro inescusável. ${ }^{32}$

O erro médico é denominado, pela doutrina, de diversas maneiras, como: erro técnico, má prática profissional, mala práxis, conduta imprópria, falha médica, etc. O erro médico pode ser definido como o resultado adverso decorrente da ação ou da omissão do médico por inobservância dos deveres jurídicos essenciais exigidos na atuação médica. Excluem-se as limitações impostas pela própria natureza da doença, bem como as lesões produzidas deliberadamente pelo médico para tratar um mal maior.

Moraes conceitua o erro médico como "a falha do médico no exercício da profissão. Excluam-se dele as da própria natureza, bem como as lesóes produzidas deliberadamente pelo profissional para o tratamento de um mal maior: ${ }^{33}$ E segue aludindo que para a caracterização do erro médico é preciso que estejam presentes:

1. o dano ao doente; 2. a ação do médico; 3. o nexo efetivo de causa e efeito entre o procedimento médico e o dano causado; 4. uma das três citadas falhas - imperícia, imprudência e negligência. A falta de qualquer desses itens discriminados descaracteriza o erro médico. Quanto à ação ou omissão do médico, no exercício profissional, causando dano à saúde do paciente, somente se lhe imputará o erro se for comprovado o nexo causal entre sua ou suas falhas e o mau resultado para o doente. ${ }^{34}$

\footnotetext{
${ }^{28}$ ATAZ LÓPEZ, Joaquín. Los médicos y la responsabilidad civil. Editorial Montecorvo: Madrid, 1985, p. 311.

${ }^{29}$ ANTUNES, João Logo. Prefácio. In: FRAGATA, José; MARTINS, Luís. O erro em medicina: perspectivas do indivíduo, da organização e da sociedade. Coimbra: Almedina, 2006, p. 29.

${ }^{30}$ ANTUNES, João Logo. Prefácio. In: FRAGATA, José; MARTINS, Luís. O erro em medicina: perspectivas do indivíduo, da organização e da sociedade, p. 29.

${ }^{31}$ DIREITO, Carlos Alberto Menezes. Erro médico. Revista de Direito Renovar, vol.o1, Rio de Janeiro, 1995, pp. 105.

${ }^{32}$ Willhelm defende que a ausência desta diferenciação gera o desestímulo da atividade médica especialmente para quem atua na área da cirurgia plástica. WILLHELM, Camila Neves. Responsabilidade civil do cirurgião plástico: obrigação de meio ou de resultado, p. 55.

${ }^{33}$ MORAES, Irany Novah. Erro médico e a justiça, p. 306.

${ }^{34}$ MORAES, Irany Novah. Erro médico e a justiça, p. 426.
} 
O erro médico, portanto, é a falha do médico no exercício da profissão excluindo de tão amplo conceito, as falhas da própria natureza, bem como as lesões produzidas deliberadamente pelo profissional para o tratamento de um mal maior, como a amputação de uma perna para o tratamento de uma gangrena que, por si só, poderia levar o paciente à morte.

Giostri conceitua o erro médico, diferenciando-o do "insucesso", que é considerado um resultado para o paciente por conta de sua resposta orgânica, como "uma falha no exercício da profissão, do que advém um mal resultado ou resultado adverso, efetivando-se através da ação ou da omissão do profissional.35

O "erro médico" pode ser definido como a conduta profissional inadequada resultante da utilização de uma técnica médica ou terapêutica incorretas que se mostra lesivas para a saúde ou vida de um paciente, podendo traduzir-se em imperícia, negligência ou imprudência.

O enfrentamento da temática impõe que sejam delimitados os contornos para a exata compreensão de seu significado, diferenciando-se do entendimento comum no qual a ação do médico é atrelada a uma expectativa de cura.

Nem todo o erro médico assumirá relevância jurídico-civil, mas apenas aquele que é susceptível de integrar ou determinar os danos causados e reunidos os demais pressupostos da responsabilidade civil, constitua o seu autor no dever de indenizar. O erro médico configura-se, deste modo, como uma falha profissional, independentemente da sua valoração jurídica e, portanto, um erro do ponto de vista técnico. Podem-se extrair as seguintes conclusões sobre a relevância jurídico-civil do erro médico: a) O erro médico que não produza resultado lesivo ou coloque em perigo grave de lesão a saúde ou a vida do paciente é irrelevante para o direito civil; b) O erro médico que não tenha sido fruto de violação dos deveres jurídicos essenciais, e não obstante toda a diligência possível do médico, tenha ocorrido, não pode ser civilmente relevante, por inexistência dos respectivos pressupostos de responsabilidade; c) A conduta médica errada que, no exercício da atividade médica que se mostre indicada para o caso, tenha observado as leges artis, seja realizada por médico ou pessoa legalmente autorizada e com intenção curativa, ainda que produza resultado infausto, no plano jurídico-civil, dependerá das circunstâncias concretas na apreciação da ilicitude e da culpa. Desta maneira, no plano jurídico-civil, relevará desde que o resultado danoso seja objetivamente imputável à conduta errada e tal conduta seja censurável ao agente a título de dolo ou de culpa, em todas as suas modalidades. ${ }^{36}$

Assim, o erro médico, em si mesmo, isto é, desligado das suas consequências, não releva para o civil, o que não quer dizer que não seja censurável noutros domínios jurídicos, como, vgg, no plano disciplinar, ou até, consoante o circunstancialismo da sua ocorrência, ética e socialmente reprovável. A importância social, médica e

\footnotetext{
${ }^{35}$ GIOSTRI, Hildegard Taggesell. Erro médico à luz da jurisprudência comentada, p. 125.

${ }^{36}$ RODRIGUES, Álvaro da Cunha Gomes. Responsabilidade civil por erro médico: esclarecimento/consentimento do doente. Revista Data Venia, n. 01, jul.-dez., 2012, p. 08.
} 
mesmo jurídica do erro médico, assim, decorre da potencialidade de tal fenômeno causar, no sentido ônticofenomenológico do termo, lesão ao corpo ou à saúde do paciente, por ação ou omissão, ou produzir um elevado risco para a integridade física do mesmo. ${ }^{37}$

\section{Classificação e Proposta de uma tipologia dos erros médicos}

A classificação dos tipos de erro médico é divergente na doutrina brasileira $38,39,40,41,42$ e também na legislação comparada ${ }^{43,44,45,46 \text {. }}$

${ }^{37}$ RODRIGUES, Álvaro da Cunha Gomes. Responsabilidade civil por erro médico: esclarecimento/consentimento do doente. Revista Data Venia, p. 08-11.

${ }^{38}$ Freire, estudioso de medicina legal no início do século, foi um dos primeiros a classificar o erro médico em três tipos: (i) Erro de tratamento; (ii) Erro de diagnóstico e; (iii) Erro na dosagem de medicamentos. FREIRE, Oscar. Pareceres. São Paulo, Saraiva, 1935 .

${ }^{39}$ Rizzardo divide em: (i) erro de diagnóstico ou profissional; (ii) erro de tratamento e; (iii) erro cirúrgico. RIZZARDO, Arnaldo. Responsabilidade civil. - 4.ed., rev. e atual., Rio de Janeiro: Forense, 2009, pp. 334-336.

${ }^{40}$ Dias trabalha com: (i) erro de técnica; (ii) erro de diagnóstico e; (iii) erro de prognóstico. DIAS, José de Aguiar. Da responsabilidade civil. 11.ed. Revista, atualizada de acordo com o Código Civil de 2002, e aumentada por Rui Berford Dias. - Rio de Janeiro: Renovar, 2006, pp. 353-354.

${ }^{41}$ Chaves propõe que os devem ser divididos em seis espécies: (i) erros de diagnóstico; (ii) faltas relativas ao tratamento; (iii) faltas por ocasião de uma operação ou intervenção; (iv) erros de prognóstico; (v) falta de higiene e; (vi) erros cometidos por radiólogos e outras especialidades, em especial anestesistas. CHAVES, Antônio. Responsabilidade das clínicas, hospitais e médicos. Responsabilidade civil do médico. Revista jurídica: órgão nacional de doutrina, jurisprudência, legislação e crítica judiciária. Ano XXXVII, núm. 159, 1991, pp. 122-124.

${ }^{42}$ Branco alude que o médico intervém diagnosticando e tratando de doenças e enfermidades, por isso fraciona o erro médico em: (i) erro no diagnóstico; e (ii) erro no tratamento. BRANCO, Gerson Luiz Carlos. Aspectos da responsabilidade civil e o dano médico. Revista dos Tribunais 733, p. 62.

${ }^{43}$ Conforme RODRIGUES, de acordo com grande parte da doutrina médica e jurídica portuguesa especializada, também destaca três modalidades de "erro médico". São eles: (i) Erro de diagnóstico; (ii) Erro de tratamento ou terapêutico; (iii) Erro na relação com o paciente. RODRIGUES, Álvaro da Cunha, Responsabilidade médica em direito penal (estudo dos pressupostos sistemáticos). Almedina, 2007, p. 293.

${ }^{44}$ Fragata e Martins enquadram os erros médicos em quatro grandes categorias: (i) Erros de diagnóstico; (ii) Erros de tratamento; (iii) Erros preventivos (falhas para providenciar o tratamento profilático adequado e monitorização inadequada ou de seguimento (follow up) do tratamento) e; Outros erros (falhas na comunicação, falhas no equipamento e outras falhas no sistema. FRAGATA, José; MARTINS, Luís. O erro em medicina: perspectivas do indivíduo, da organização e da sociedade. Coimbra: Almedina, 2006, p. 29.

${ }^{45}$ Leape e outros dividem os erros médicos em: (i) Diagnostic: error or delay in diagnosis, failure to employ indicated tests, use of outmoded tests or therapy, failure to act on results of monitoring or testing; (ii) Treatment: error in the performance of an operation, procedure, or test, error in administering the treatment, error in the dose or method of using a drug, avoidable delay in treatment or in responding to an abnormal test, inappropriate (not indicated) care; (iii) Preventive: failure to provide prophylactic treatment Inadequate monitoring or follow-up of treatment; (iv) Other: failure of communication, equipment failure and other system failure. LEAPE, Lucian; LAWTHERS, Ann G.; BRENNAN, Troyen A., et al. Preventing Medical Injury. Quality Review Bulletin. núm 19, 1993, 144-149; A apresentação dos erros médicos a partir de uma taxonomia quase exaustiva de suas modalidades, da autoria podemos encontrar na obra americana: KOHN, L.T; CORRIGAN, J.M; DONALDSON, M.S. To err is human: building a safer health system. Washington, DC: National Academy Press, 2000.

${ }^{46}$ No Direito Italiano, classifica-se o erro médico em quatro tipos: " (i) Errore di diagnose: per mancato od inesatto inquadramento medico; uma affezione morbosa a seguito di insuficiente raccolta anamnestica, superficialità od incompletezza dell' esame obiettivo o mancata esecuzione di esami strumentali o di laboratorio. Esiste una sorta di proporzione inversa tra l'errore diagnostico e la difficoltà del caso. Esiste altresi un minuto livello di preparazione medica al di sotto del quale ogni manchevolezza diagnostica è di per sé errore; (ii) Errore di scelta di trattamento: spesso conseguenza dell 'errore di diagnosi, che implica la mancata valutazione delle opzioni di scelta nella terapia di un determinato caso clinico; (iii) Errore di esecuzione di trattamento: per scelta non correta 
O fato de existirem poucas classificações dos tipos de erro médico está relacionado com a falta de informação sobre a temática, porque eles são o resultado de cadeias de eventos raramente estudados, relatos inadequados de erros por parte dos médicos, variações ou mesmo ignorância da definição de erro médico.

A maior parte da doutrina se resume a tratar o erro médico como a caracterização da culpa, em suas modalidades, sendo erro médico as situações nas quais o médico age com negligência, imprudência ou imperícia. Poucos autores tentaram agrupar as espécies de erro médico.

Propõe-se que os erros médicos podem ser agrupados em três tipos: (i) erro de diagnóstico; (ii) erro de tratamentoe; (iii) erro na relação com o paciente.

O diagnóstico ${ }^{47}$ é o primeiro ato médico realizado pelo profissional anteriormente à indicação do tratamento adequado. $\mathrm{O}$ médico, no diagnóstico, reconhece os diferentes signos e sinais que caracterizam as enfermidades (observação dos aspectos objetivos) e os sintomas sobre os quais o paciente o alerta (apreciação subjetiva). Utiliza-se de sua experiência clínica e os métodos científicos para, acrescido dos resultados experimentais de exames, radiografias, etc., chegar a uma indicação, ou não, cirúrgica. ${ }^{48}$

O conceito de diagnóstico em Medicina é de uma amplitude admirável. Pode-se conceituá-lo como o parecer do médico sobre o estado do paciente após a anamnese. É momento no qual se informa ao paciente qual é a doença ou mal que lhe afeta, após buscar junto a este as informações necessárias. Trata-se de um processo de identificação de uma doença com base nos sinais e sintomas que o doente apresenta. ${ }^{49}$

O diagnóstico, como bem lembra Branco, é o momento no qual se informa ao paciente qual é a doença ou mal que lhe afeta, sendo, talvez, o momento mais importante da intervenção médica, haja vista que um erro nesse momento poderá comprometer não só a possibilidade de cura, mas também trazer danos não previsíveis para o tratamento. ${ }^{50}$

A formação do diagnóstico tem uma série de obrigações científicas mínimas a serem cumpridas ${ }^{51}$, que

del farmaco e dosaggio incongruo, in particolare in ambito di antibioticoterapia, od errore di manualitaj; (iv) Errore di prognosi, peraltro spesso irrilevante nella causazione del danna materiale."AA.VV. Medicina Legale - Edizioni Giuridiche Simone, 2012, p. 210.

${ }^{47}$ "El término diagnóstico se deriva del griego diagnostikós y significa "distinto, que permite distinguir", derivado de diagignóstkein "distinguir, discernir" y este de gignóskein "conocer". REAL ACADEMIA ESPAÑOLA. Diccionario de la lengua española. Tomo I. Vigésimo segunda edición. Espasa Calpe: Madrid. 2001.

${ }^{48}$ GHERSI, Carlos A. (dir.). Responsabilidad profesional. Ed. Astrea, Buenos Aires, 1998, p. 21.

${ }^{49}$ GUIMARÃES, Deocleciano Torrieri (org.). Dicionário de termos médicos, enfermagem e radiologia, p. 140.

${ }^{50}$ BRANCO, Gerson Luiz Carlos. Aspectos da responsabilidade civil e o dano médico. Revista dos Tribunais 733, p. 62.

${ }^{51}$ Falando sobre os erros de diagnóstico, que decorrem, normalmente, do resultado de várias falhas no processo de diagnóstico e de vários fatores que contribuem, de acordo com a sua origem pode ser classificados em "I. Errores cognitivos (Cognitive errors): se reflejan en las fallas diagnósticas debido a una mala recolección de datos o interpretación de estos, fallas en el razonamiento o conocimiento incompleto. Su origen se centra en las limitaciones del proceso humano de la información y los sesgos producidos al utilizar la heurística, lo que garantiza que este tipo de errores persistirán. 2. Errores del sistema (System errors): estos se presentan cuando un diagnóstico es retrasado o no se realiza debido a las fallas latentes en los sistemas de salud. 3. Errores sin culpa ("No fault" errors): ocurren cuando la presentación del cuadro clínico es silenciosa, atípica, o miméticas de algún cuadro más común." 
partem do interrogatório, no qual se realizará a identificação do paciente, a valoração do seu estado geral de saúde, investigações com base na tecnologia, tudo incorporado ao seu histórico clínico. ${ }^{52}$ Para formular o diagnóstico, o médico necessita de algumas mínimas informações científicas prévias. Primeiramente, o interrogatório será fonte de informações sobre a identidade do paciente, seu grupo familiar, etc. Ainda, o médico analisará o estado geral de saúde do paciente, através do seu peso, pulso, temperatura, pressão arterial, etc. Por fim, será munido, se necessário, de informações tecnológicas decorrentes de sua investigação científica que lhe darão firmeza suficiente para formular o diagnóstico. ${ }^{53} \mathrm{E}$, uma vez conhecido este diagnóstico, o paciente deverá ser informado sobre todos os riscos do procedimento indicado ao qual se submeterá.

É muito comum que frente a determinados sintomas o médico opte por determinado diagnóstico ou tratamento dentre os vários cientificamente indicados e, mais tarde, se verifique que o elegido não era o mais indicado. Caso a sua escolha esteja dentro dos aconselhados prima facie pela ciência médica, não incidirá em responsabilização civil. ${ }^{54}$

O erro de diagnóstico, nas palavras de Carvalho, "é fruto, quase sempre, de uma investigação mal realizada, quase sempre marcada pela insuficiência dos meios utilizados ou pela negligência do investigador. ${ }^{55}$ Pode se dar em face de ato pessoal do profissional ou, ainda, por ato do próprio paciente, quando, por exemplo, omite informação ao médico. Não se pode esquecer, também, o fato de que a falha nos exames complementares podem induzir a uma posição em relação ao tratamento. No caso de o paciente informar e/ou omitir informações ao médico, ainda que não dolosamente, ocorrerá o rompimento do nexo de causalidade. Assim, o médico só será responsável em indenizar o paciente, pelo erro de diagnóstico, se ficar provada a ocorrência de algum dano. No erro de diagnóstico, Stoco distingue o erro de procedimento do erro no procedimento. Quando o diagnóstico estiver correto e o profissional tenha identificado o mal de que padece a pessoa, estar-se-á diante de um erro de procedimento; de outro lado, quando o diagnóstico foi correto e adequado, mas houve falha profissional, durante o procedimento, o médico incorrerá em erro no procedimento. ${ }^{56}$

Três situações podem ocorrer em relação ao diagnóstico realizado por ato pessoal: a omissão na realização do diagnóstico, o atraso ou a realização de diagnóstico equivocado. A falha na prestação do serviço somente ocorrerá se a conduta realizada não for similar àquela que se poderia esperar de um médico nas mesmas

ALVARADO-GUEVARA, Ana Teresa; FLORES-SANDI, Grettchen. Errores médicos. Acta médica costarricense, vol.51, núm.01, 2009, p. 20.

${ }^{52}$ GHERSI, Carlos A. La responsabilidad de los médicos frente a los pacientes. In: GHERSI, Carlos A; WEINGARTNER, Célia. Tratado de derecho a la salud - Tomo II, p. 197.

${ }^{53}$ GHERSI, Carlos A. La responsabilidad de los médicos: factores de atribución. In: GHERSI, Carlos A; WEINGARTNER, Célia. Tratado de derecho a la salud - Tomo II, p. 196.

${ }^{54}$ FERREIRA, Roberto Vázquez. Daños y perjuicios en el ejercicio de la medicina, p. 124

${ }^{55}$ CARVALHO, José Carlos Maldonado de. Iatrogenia e erro médico sob o enfoque da responsabilidade civil, p. 57. vol.11, no. 02, Rio de Janeiro, 2018. pp. 1963 - 1983 
circunstâncias enfrentadas pelo médico que realizou o ato. ${ }^{57} \mathrm{O}$ diagnóstico esperado não é aquele considerado correto, mas de acordo com a atenção e as precauções indicadas pela ciência médica atual.

Haverá responsabilidade civil médica, levando-se em conta o risco envolvido no diagnóstico e a preservação dos critérios subjetivos científico-discricionário do médico, quando o médico agiu com culpa. Ao averiguar a culpa do médico frente ao erro de diagnóstico, deve-se levar em conta a conduta do profissional, isto é, se houve a escolha de um tratamento inadequado à patologia, se o diagnóstico foi feito às pressas, se ocorreu erro grosseiro, ou seja, se o tratamento foi utilizado inadequadamente, atitude essa que qualquer médico prudente, atuando nas mesmas condições externas que o demandado, não utilizaria por ser de notável percepção o erro. A questão deverá ser baseada pela regra geral: se, naquelas circunstâncias, com os meios de que dispunha, o profissional não se desviou crassamente da conduta prevista para aquele caso, inexistirá culpa - portanto, inexistirá o dever de indenizar. Contudo, o contrário ocorrerá (dever de indenizar), se o médico não utilizou todos os recursos à sua disposição, como, por exemplo, não analisando cuidadosamente a doença de seu paciente, não realizando todos os exames necessários para elevar o grau de certeza diagnóstica, sem dúvida errou em sua conduta e, por isso, deverá ser responsabilizado civilmente.

Como dizem Direito e Cavalieri Filho, "o clínico, na verdade, é um cão-perdigueiro, que deve farejar tudo, buscar cada possibilidade diagnóstica, exaustivamente." Ao averiguar a responsabilidade civil por erro de diagnóstico, o juiz deverá investigar todos os cuidados que foram dispensados ao paciente lesado, como a atenção, o tipo de exame, as possibilidades para a investigação científica de acordo com o momento científico, de modo que a desatenção, negligência são elementos suficientes para constatação da culpa do médico. ${ }^{58}$

Quando o erro de diagnóstico for escusável, não se poderá imputar a responsabilidade ao médico, já que se está diante de conhecimento médico que não é necessariamente infalível. O médico deve tratar do paciente com zelo e diligência, proporcionando todos os recursos que a ciência médica oferece. ${ }^{59}$

Devem ser analisados dois fatores determinantes de tal irresponsabilidade: se o erro é escusável em face do atual estado da ciência médica e não tenha acarretado danos ao paciente. Desta maneira, a priori, o erro de diagnóstico é considerado escusável, a não ser que se comprove que se trata de erro grosseiro, ou seja, presente a

\footnotetext{
${ }^{56}$ STOCO, Rui. Tratado de responsabilidade civil: doutrina e jurisprudência. - 8.ed., rev. atual. e ampl. São Paulo: Editora Revista dos Tribunais, 2011, p. 626.

${ }^{57}$ FERRAZ, Octávio Luiz Motta. Responsabilidade civil da atividade médica no código de defesa do consumidor. - Rio de Janeiro: Elsevier, 2009, pp. 154-155.

${ }^{58}$ Direito e Cavalieri Filho dizem que não há necessidade de erro grosseiro para a configuração da responsabilidade médica. Referem que "o que o juiz deve examinar são as condiçōes da atuação do médico na elaboração do diagnóstico, sem qualquer adjetivo, mesmo porque em medicina a situação do paciente, as condiçóes disponíveis para a elaboração do diagnóstico e a capacitação do profissional são elementos importantes para que seja imposta a obrigação de indenizar."DIREITO, Carlos Alberto Menezes; CAVALIERI FILHO, Sérgio. Comentários ao novo código civil, volume XIII: da responsabilidade civil, das preferências e privilégios creditórios, pp. 443-445.
} 
culpa, em qualquer de suas modalidades. Na avaliação da culpa médica, deve-se ter em conta que a própria ciência médica impossibilita o acesso à totalidade da certeza fornecida pelo conhecimento médico-científico. Deve-se, então, aquilatar este elemento de acordo com o desenvolvimento atual da ciência médica, salvo em casos excepcionais. ${ }^{60}$ Se restar comprovado que o médico cumpriu com seus deveres jurídicos essenciais, efetuando uma anamnese completa, atento aos meios técnicos atualizados e disponíveis, entende-se que não será caso de responsabilidade civil médica. Pensar contrariamente, seria impor ao médico um encargo de infalibilidade contrário à própria essência humana. Como alude Trigo Represas:

responderá pues de toda negligencia, imprudencia o impericia, cuya apreciación habrá de hacerse en abstracto y tomando como modelo de comparación al arquétipo del 'buen profesional: 'ni el mejor, ni el superhombre de Nietzche, ni un héroe, pero tampoco el peor, el descuidado, el ignorante, el desidioso o desaprensivo. ${ }^{61}$

O erro de tratamento ocorre posteriormente ao diagnóstico, quando o médico indicará os meios, os medicamentos e as condutas para o tratamento do paciente. ${ }^{62}$ Inclui falhas em qualquer fase do processo de prestação de serviços de cuidados com a saúde, tanto na tomada de decisão, quanto na execução da técnica.

São alguns exemplos de erro de tratamento o erro na realização de uma operação ou procedimento, o erro na administração do tratamento, o erro na dose de medicação ou seu método de uso, o atraso no tratamento ou na resposta à situação que os testes diagnósticos indicaram e a prestação de serviços não apropriados para aquele paciente. ${ }^{63}$

Consistirá, portanto, em erro no tratamento não apenas o erro na execução de uma cirurgia, por exemplo, mas também o descuido com elementos secundários que possam trazer prejuízo, problema de infecção hospitalar provocada pela falta de higiene e descuido na utilização dos equipamentos. ${ }^{64}$

O erro na relação com os pacientes agrupa as demais formas de erros médicos que não se encaixam no erro de diagnóstico e no erro de tratamento.

Neste caso, envolvem questões de comunicação, de relacionamento e ainda as demais que podem ocorrer tanto na fase pré-contratual, como na fase pós-contratual, na medida em que ocorram transgressões às regras tidas como recomendáveis e aplicáveis à relação médico-paciente. Nesta espécie de erro médico incluem-se os erros preventivos, como: a falha em providenciar tratamento profilático adequado, a monitoração inadequada,

\footnotetext{
${ }^{59}$ ANDREONI, Wilson Rubens. Cirurgia plástica - obrigação de meio. In: AVELAR, Juarez Moraes. Cirurgia plástica: obrigação de meio e não obrigação de fim ou de resultado, p. 426.

${ }^{60} \mathrm{CHAVES}$, Antônio. Responsabilidade das clínicas, hospitais e médicos. Responsabilidade civil do médico. Revista Jurídica: órgão nacional de doutrina, jurisprudência, legislação e crítica judiciária, p. 125.

${ }^{61}$ TRIGO REPRESAS, Félix A. Reparación de daños por "mala praxis" médica, p. 40.

${ }^{62}$ RIZZARDO, Arnaldo. Responsabilidade civil, p. 336.

${ }^{63}$ ANTUNES, João Logo. Prefácio. In: FRAGATA, José; MARTINS, Luís. O erro em medicina: perspectivas do indivíduo, da organização e da sociedade, p. 62.

${ }^{64}$ BRANCO, Gerson Luiz Carlos. Responsabilidade civil por erromédico: aspectos. Revista Síntese de Direito Civile Processual Civil, p. 137.
} 
falha de comunicação com o paciente, falha no equipamento, etc.

Tais erros médicos decorrem da violação e/ou descumprimento, por parte do médico, dos deveres jurídicos essenciais, como o erro em relação ao prognóstico. Desta maneira, analisadas as espécies de erro médico, importante diferenciar o erro médico da iatrogenia.

\section{Erro médico e Iatrogenia}

Todo procedimento médico, por mais simples que seja, possui potencial risco danoso em graus variáveis, inclusive o risco da morte. Há reações corporais que se situam em terreno para além da atual compreensão e justificativas técnico-científicas. As denominadas complicações ou intercorrências, nesse passo, não se confundem com a iatrogenia, que deriva do correto agir médico, de acordo com os parâmetros científicos. As complicações ou intercorrências se reportam a eventos danosos ao paciente, oriundos não de ato médico isolado, mas de diversos fatores, como reações adversas do organismo, imunodeficiências, uso de drogas, etc. Nesses dois casos, se o agir médico não for falho, não incidirá a obrigação de indenizar, já que se enquadram nas hipóteses de caso fortuito ou força maior. ${ }^{65}$

O exercício da atividade médica, sob o ponto de vista estritamente jurídico, consiste em um exercício regular de uma faculdade legítima ${ }^{66}$, já que constitui um meio justo a um fim lícito e adequado, reconhecido pela ordem estatal. De modo que as lesões são permitidas e lícitas, uma vez que tem o objetivo de cura ou melhora mais favorável ao paciente. Conforme Moraes, três tipos de sequelas decorrentes do procedimento clínico: as lesões previsíveis e também esperadas; as previsíveis, mas inesperadas, decorrentes do perigo inerente a todo e qualquer procedimento e as falhas decorrentes do comportamento humano no exercício da profissão, passíveis de suscitar o problema da responsabilidade legal. ${ }^{67}$ Somente as lesões previsíveis - esperadas ou não - e que decorrem do natural procedimento médico é que podem ser conceituadas como iatrogênicas. As demais, que resultem de comportamento culposo, ingressarão no campo da responsabilidade civil.

Fator preponderante para a irresponsabilidade do profissional será o conhecimento profundo das respostas do organismo humano relativamente a qualquer prescrição medicamentosa e de seu mecanismo de ação, inclusive quanto aos efeitos colaterais. Diante da correta prescrição e de tal prévia avaliação criteriosa os resultados indesejáveis - iatrogênicos, por natureza - não serão passíveis de atestar sua culpa.

Entende-se que iatrogenia é:

a ocorrência de danos ou lesões físicos, psíquicos, farmacológicos ou instrumentais,

\footnotetext{
${ }^{65}$ BARROS JÚNIOR, Edmilson de Almeida. A responsabilidade civil do médico: uma abordagem constitucional. - São Paulo: Atlas, 2007, pp. 96-101.

${ }^{66}$ STOCO, Rui. Iatrogenia e responsabilidade civil do médico. Revista dos Tribunais, vol.789, p. 108.

${ }^{67}$ MORAES, Irany Novah. Erro médico e a justiça, p. 489.
} 
provocados, porém, por um procedimento médico de manifesto propósito benéfico, que não configure negligência, imprudência e imperícia." Trata-se de "um estado ou prejuízo provocado por ato médico em pessoas sadias ou doentes, cujos transtornos são imprevisíveis e inesperados. ${ }^{68}$

A iatrogenia caracteriza erro escusável como aquele que não gera a responsabilidade em qualquer de suas esferas civil, penal ou administrativa.

Alguns autores dividem a iatrogenia em lato sensu, que açambarca tanto o atuar correto, lícito médico, quanto o ilícito e a stricto sensu, que é aquela que abrange a lesão causada ao paciente, mas decorrente de um agir médico correto, cauteloso e dentro das recomendações médicas rotineiras. ${ }^{69}$

E outros, como Stoco, aludem que a iatrogenia é uma "alteração patológica provocada no paciente por tratamento de qualquer tipo". Seria, portanto, um acontecimento ou resultado danoso, no mundo físico juridicamente considerado fato lato sensu - que decorre da atuação médica. Para o autor:

a iatrogenia como dano à pessoa - quando decorra de uma conduta culposa do agente, e, assim, se possa identificar um nexo etiológico entre essa conduta e o resultado iatrogênico transforma o fato danoso em ato ilícito, insere-se na teoria da culpa e passa a ser regida pelas regras da responsabilidade civil. ${ }^{70}$

Portanto, constatada a iatrogenia, a implicação automática será a ruptura do nexo de causalidade entre o dano sofrido e a conduta médica, ainda que causados danos ao paciente. ${ }^{71}$ A lesão iatrogênica é aquela causada pelo agir correto do médico, em observância das normas e dos princípios da ciência médica. ${ }^{72}$

\footnotetext{
${ }^{68}$ BARBOSA, Heloisa Helena. Responsabilidade civil em face das pesquisas em seres humanos: efeitos do consentimento livre e esclarecido. In: MARTINS-COSTA, Judith; MÖLLER, Letícia Ludwig (orgs.). Bioética e responsabilidade. Rio de Janeiro: Forense, 2009, p. 215.

${ }^{69}$ SOUZA, Alex Pereira de; COUTO FILHO, Antônio Ferreira. A improcedência no suposto erro médico, p. 33.

${ }^{70}$ STOCO, Rui. Iatrogenia e responsabilidade civil do médico. Revista dos Tribunais, vol.789, p. 110.

${ }^{71}$ No sentido de excluir a responsabilidade do profissional que atua de forma adequada e diligente, ainda que sobrevenha resultado danoso ao paciente manifestou-se o TJRJ: "Indenização por danos materiais e morais. Cirurgia redutora de mamárias. Mulher idosa. Seios volumosos. Procedimento cirúrgico reduziu consideravelmente o volume dos seios. Infecção decorrente do excesso de gordura no local tem origem da reação do próprio organismo. Prova pericial demonstrou que a técnica cirúrgica adequada fora utilizada, bem como presente a habilidade do cirurgião. Frustração da apelante sobre o resultado esperado é insuficiente para proporcionar a verba reparatória. Hospital correu não teve nenhuma participação que contribuísse na insatisfação da apelante. Recorrente apresentava problema de saúde, inclusive, assaduras na região dos seios, antes de se submeter à cirurgia. Peculiaridades outras não interferiram no desfecho cirúrgico. Ausência de responsabilidade dos apelados. Apelo desprovido." Transcrevemos curioso trecho do voto condutor deste julgado que aludiu que: "questóes estéticas devem observar inúmeros fatores, mesmo porque, como a própria apelante expôs o tamanho de seus seios era bem destacado, basta a referência do número do sutiã, ou seja, 54, portanto, a cirurgia plástica tem suas limitações, porém, não está apta a proporcionar metamorfose, enquanto que o processo infeccioso decorrente de excesso de gordura no local faz parte do imponderável, ocorrendo as mais diversas alteraçóes do organismo humano e variando de pessoa a pessoa." BRASIL. Tribunal de Justiça do Estado de São Paulo. Apelação Cível no 0337721-98.2009.8.26.0000. Quarta Câmara de Direito Privado. Apelante: Zenaide Silva Fraguas. Apelado: Fundação para o progresso da Cirurgia e Outros. Rel. Des. Natan Zelinschi de Arruda. São Paulo, em 12/08/2010. Disponível em: <http://www.tjsp.gov.br>.Acesso em: 14.08.2016.

${ }^{72}$ BARROS JÚNIOR, Edmilson de Almeida. A responsabilidade civil do médico: uma abordagem constitucional, p. 65.
} 


\title{
CONCLUSÃO
}

Aplainados os principais conceitos, além de desenvolvidas as linhas gerais, passa-se a conclusão, referindo-se, inicialmente, que é imanente ao ser humano a falibilidade. Na seara médica, ainda mais, em razão de particular ofício, a falibilidade é posta em risco muitas vezes constante. Este risco, portanto, é inerente à própria atividade médica.

Entretanto, em algumas circunstâncias a falibilidade transcende o limite de contato com o erro médico, o que pode gerar a responsabilização civil médica por este ato.

É possível estabelecer, ainda, a diferença entre culpa médica e erro profissional, muitas vezes utilizado erroneamente como sinônimo de negligência, e está em que o erro profissional ocorre quando a conduta médica é correta, mas a técnica empregada é incorreta; de outro lado, haverá culpa médica quando a técnica utilizada for correta, mas a conduta médica for considerada incorreta.

Já quanto ao erro médico propriamente dito, há diversas correntes e manifestações de doutrinadores classificando-os de diversas formas. Propõe-se, no presente ensaio, que os erros médicos possam ser agrupados em três tipos: (i) erro de diagnóstico; (ii) erro de tratamento e; (iii) erro na relação com o paciente, sendo possível coligar os erros médicos em uma determinada classificação aplicável a todos os casos de responsabilidade civil por erro médico.

Por fim, a iatrogenia em relação ao erro médico não se trata de erro, mas são danos causados, entretanto por meio de um procedimento com o intento benéfico, o que não configura a culpa.

\section{BETWEEN THE HUMAN FALLIABILITY AND THE MISTAKE: A PROPOSE OF DELIMITATION AND CLASSIFICATION OF THE MEDICAL ERROR}

\begin{abstract}
This article intends to discuss the medical mistake, presenting the limitations between the human fallibility and the mistake. In this area, it investigates the guilt and the professional mistake. Moreover, it studies the civil-legal delimitation and the consequences of the medical mistake, proposing, in the end, a classification from a species typology of the medical mistake. Lastly, it develops the subject involving iatrogenic. By a bibliographic and documentary analysis, it promotes a dialogue between the contributions of the civil responsibility and the limits of the mistake and human fallibility. Lastly, it concludes that the medical mistake can be classified as a diagnosis mistake, treatment mistake and mistake in the medical-patient relationship.
\end{abstract}

Keywords: Medical Mistake; Classification; Civil Responsibility; Civil Code; Consumer Defense Code. 


\section{REFERENCIAS}

AA.VV. Medicina Legale. - Edizioni Giuridiche Simone, 2012.

ALVARADO-GUEVARA, Ana Teresa; FLORES-SANDI, Grettchen. Errores médicos. Acta médica costarricense, vol.51, núm.01, 2009

AGUIAR JÚNIOR, Ruy Rosado de. Responsabilidade civil do médico. Revista Jurídica: órgão nacional de doutrina, jurisprudência, legislação e crítica judiciária. Ano XLV, n. 231, 1997, pp. 122-147.

ANDREONI, Wilson Rubens. Cirurgia plástica - obrigação de meio. In: AVELAR, Juarez Moraes. Cirurgia plástica: obrigação de meio e não obrigação de fim ou de resultado. - São Paulo: Hipócrates, 2000, pp. 421-436.

ANTUNES, João Logo. Prefácio. In: FRAGATA, José; MARTINS, Luís. O erro em medicina: perspectivas do indivíduo, da organização e da sociedade. Coimbra: Almedina, 2006.

ATAZ LÓPEZ, Joaquín. Los médicos y la responsabilidad civil. Editorial Montecorvo: Madrid, 1985.

BARBOSA, Heloisa Helena. Responsabilidade civil em face das pesquisas em seres humanos: efeitos do consentimento livre e esclarecido. In: MARTINS-COSTA, Judith; MÖLLER, Letícia Ludwig (orgs.). Bioética e responsabilidade. Rio de Janeiro: Forense, 2009, pp. 205-234.

BARROS JÚNIOR, Edmilson de Almeida. A responsabilidade civil do médico: uma abordagem constitucional. São Paulo: Atlas, 2007.

BRANCO, Gerson Luiz Carlos. Responsabilidade civil por erro médico: aspectos. Revista Síntese de Direito Civil e Processual Civil, núm. 04, Ed. Síntese, mar--abr, 2000, pp. 128-151.

CARVALHO, José Carlos Maldonado de. Iatrogenia e erro médico sob o enfoque da responsabilidade civil. 3.ed., rev. e ampl. Rio de Janeiro: Editora Lumen Juris, 2009.

CAVALIERI FILHO, Sérgio. Programa de responsabilidade civil. 8.ed. - São Paulo: Atlas, 2008.

CHAVES, Antônio. Responsabilidade das clínicas, hospitais e médicos. Responsabilidade civil do médico. Revista Jurídica: órgão nacional de doutrina, jurisprudência, legislação e crítica judiciária. Ano XXXVII, núm. 159, 1991, pp. 119-147.

DIAS, José de Aguiar. Da responsabilidade civil. 11 .ed. Revista, atualizada de acordo com o Código Civil de 2002, e aumentada por Rui Berford Dias. - Rio de Janeiro: Renovar, 2006.

DIREITO, Carlos Alberto Menezes; CAVALIERI FILHO, Sérgio. Comentários ao novo código civil, volume XIII: da responsabilidade civil, das preferências e privilégios creditórios. - Rio de Janeiro: Forense, 2004.

DIREITO, Carlos Alberto Menezes. Erro médico. Revista de Direito Renovar, vol.01, Rio de Janeiro, 1995, pp. 101-110.

FERRAZ, Edmundo Machado; NOGUEIRA, Roberto Wanderley. Erro médico e prática não médica. In: FIGUEIREDO, Antônio Macena de; LANA, Roberto Lauro. Direito médico: implicações éticas e jurídicas na 
prática médica. Rio de Janeiro: Lumen Juris, 2009, pp. 347-373.

FERRAZ, Octávio Luiz Motta. Responsabilidade civil da atividade médica no código de defesa do consumidor. Rio de Janeiro: Elsevier, 2009.

FERREIRA, Roberto Vázquez. Daños y perjuicios en el ejercicio de la medicina. 2.ed, Colección "Responsabilidad Civil", vol. 12, Buenos Aires: Hammurabi, 2002.

FRADERA, Véra Maria Jacob de. Responsabilidade civil dos médicos. Revista AJURIS 55. Porto Alegre, jul. 1992, pp. 116-139.

FRAGATA, José; MARTINS, Luís. O erro em medicina: perspectivas do indivíduo, da organização e da sociedade. Coimbra: Almedina, 2006

FRANÇA, Genival. Direito médico. - 11.ed., rev., atual. e ampl. - Rio de Janeiro: Forense, 2013.

FREIRE, Oscar. Pareceres. São Paulo, Saraiva, 1935.

GHERSI, Carlos A. (dir.). Responsabilidad profesional. Ed. Astrea, Buenos Aires, 1998.

La responsabilidad de los médicos frente a los pacientes. In: GHERSI, Carlos A; WEINGARTNER, Célia. Tratado de derecho a la salud - Tomo II. 1.ed. - Buenos Aires: La Ley, 2012, pp. 195-210.

La responsabilidad de los médicos: factores de atribución. In: GHERSI, Carlos A; WEINGARTNER,

Célia. Tratado de derecho a la salud - Tomo II. 1.ed. - Buenos Aires: La Ley, 2012, pp. 179-194.

GIOSTRI, Hildegard Taggesell. Erro médico à luz da jurisprudência comentada. 2.ed. Curitiba: Juruá, 2004.

GOMES, Júlio Cezar Meirelles; FRANÇA, Genival Veloso de. Erro médico. In: COSTA, Sergio Ibiapina Ferreira; OSELKA, Gabriel; GARRAFA, Volnei. (orgs.) Iniciação à bioética. - Brasília: Conselho. Federal de Medicina, 1998.

GUIMARÃES, Deocleciano Torrieri (org.). Dicionário de termos médicos, enfermagem e radiologia. 4.ed. - São Paulo: Rideel, 2010.

KOHN, L.T; CORRIGAN, J.M; DONALDSON, M.S. To err is human: building a safer health system. Washington, DC: National Academy Press, 2000.

LEAPE, Lucian; LAWTHERS, Ann G.; BRENNAN, Troyen A., et al. Preventing Medical Injury. Quality Review Bulletin. núm 19, 1993, 144-149.

LÓPEZ, Pedro Rodríguez. Responsabilidad médica y hospitalaria. Bosch, 2004.

LOVECE, Graciela. Daños derivados de los cirujanos estéticos. In: GHERSI, C. (Dir.); WEINGARTNER, C. (coord.). Tratado de daños reparables, Ed. La Ley, Buenos Aires, 2008.

MELLO FILHO, Jonas de. Erro médico. In: PEREIRA, Hélio do Valle; ENZWEILER, Romano José. Curso de direito médico. - São Paulo: Conceito Editorial, 201 1, pp.323-350. 
MINOSSI, José Guilherme. Prevenção de conflitos médico-legais no exercício da medicina. Revista do Colégio Brasileiro de Cirurgiões, vol.36, núm.1, 2009, pp. 90-95.

MORAES, Irany Novah. Erro médico e a justiça. 5.ed. rev., atual. e ampl. - São Paulo: Editora Revista dos Tribunais, 2003.

POLICASTRO, Décio. Erro médico e suas consequências jurídicas. 3.ed., rev., atual. e ampl. - Belo Horizonte: Del Rey, 2010.

REAL ACADEMIA ESPAÑOLA. Diccionario de la lengua española. Tomo I. Vigésimo segunda edición. Espasa Calpe: Madrid. 2001.

RIZZARDO, Arnaldo. Responsabilidade civil. - 4.ed., rev. e atual., Rio de Janeiro: Forense, 2009.

RODRIGUES, Álvaro da Cunha Gomes. Responsabilidade civil por erro médico: esclarecimento/consentimento do doente. Revista Data Venia, núm. 01, jul.-dez., 2012, pp. 06-23.

SÃO PAULO. Assembleia legislativa. Relatório final da comissão parlamentar de inquérito sobre erro médico. Disponível em: <http://www.al.sp.gov.br/StaticFile/documentacao/cpi_erro_medico_relatorio_final.pdf>. Acesso em: 25 jan. 2017.

SILVA, Regina Beatriz Tavares da. Pressupostos da responsabilidade civil na área da saúde: ação, dano e nexo causal. Fundamentos da responsabilidade civil na área da saúde: culpa ou risco. A prova. In: SILVA, Regina Beatriz Tavares da. (Org.). Responsabilidade civil na área da saúde. 2.ed.São Paulo: Saraiva, 2009, pp. 03-35.

SOUZA, Alex Pereira de; COUTO FILHO, Antônio Ferreira. A improcedência no suposto erro médico. Rio de Janeiro: Lumen Juris, 2002.

SOUSA, Isa António de. A responsabilidade do Estado por actos médicos: entre a "présomption de faute" francesa e a "objectivização" espanhola - breve resenha comparativa: uma convergência de regimes? Revista da Faculdade de Direito da Universidade Lusófona do Porto, vol. 2, núm. 2, 2013, pp. 96-116.

STOCO, Rui. Tratado de responsabilidade civil: doutrina e jurisprudência. - 8.ed., rev. atual. e ampl. São Paulo: Editora Revista dos Tribunais, 2011.

Iatrogenia e responsabilidade civil do médico. Revista dos Tribunais, vol.789, 2001, pp. 105-110.

TRIGO REPRESAS, Félix A.. Reparación de daños por "mala praxis" médica. 2.ed, act. y ampl. Buenos Aires: Hammurabi, 2008.

WILLHELM, Camila Neves. Responsabilidade civil do cirurgião plástico: obrigação de meio ou de resultado. Porto Alegre: Stampa, 2009.

Trabalho enviado em 11 de agosto de 2017.

Aceito em 09 de novembro de 2017. 